\title{
Correction to: Hearing dogs for people with severe and profound hearing loss: a wait- list design randomised controlled trial investigating their effectiveness and cost- effectiveness
}

Lucy Stuttard ${ }^{1 *}$, Philip Boyle ${ }^{1}$, Caroline Fairhurst ${ }^{2}$, Catherine Hewitt ${ }^{2}$, Francesco Longo ${ }^{3}$, Simon Walker ${ }^{3}$, Helen Weatherly ${ }^{3}$, Emese Mayhew ${ }^{1}$ and Bryony Beresford ${ }^{1}$

Correction to: Trials 22, 700 (2021).

https://doi.org/10.1186/s13063-021-05607-9

Following the publication of the original article [1], we were notified of the below:

1. The flow of participants from randomisation to T1 was missing in Fig. 1. Originally published vs. corrected Fig. 1 are presented below

The original article can be found online at https://doi.org/10.1186/s13063021-05607-9.

* Correspondence: lucy.stuttard@york.ac.uk

'Social Policy Research Unit, Department of Social Policy and Social Work,

Church Lane Building, York Science Park, University of York, York, Heslington YO10 5DF, UK

Full list of author information is available at the end of the article

(c) The Author(s). 2021 Open Access This article is licensed under a Creative Commons Attribution 4.0 International License, which permits use, sharing, adaptation, distribution and reproduction in any medium or format, as long as you give appropriate credit to the original author(s) and the source, provide a link to the Creative Commons licence, and indicate if changes were made. The images or other third party material in this article are included in the article's Creative Commons licence, unless indicated otherwise in a credit line to the material. If material is not included in the article's Creative Commons licence and your intended use is not permitted by statutory regulation or exceeds the permitted use, you will need to obtain permission directly from the copyright holder. To view a copy of this licence, visit http://creativecommons.org/licenses/by/4.0/. The Creative Commons Public Domain Dedication waiver (http://creativecommons.org/publicdomain/zero/1.0/) applies to the data made available in this article, unless otherwise stated in a credit line to the data. 
Originally published Fig. 1

CONSORT Flow Diagram: enrolment to T1

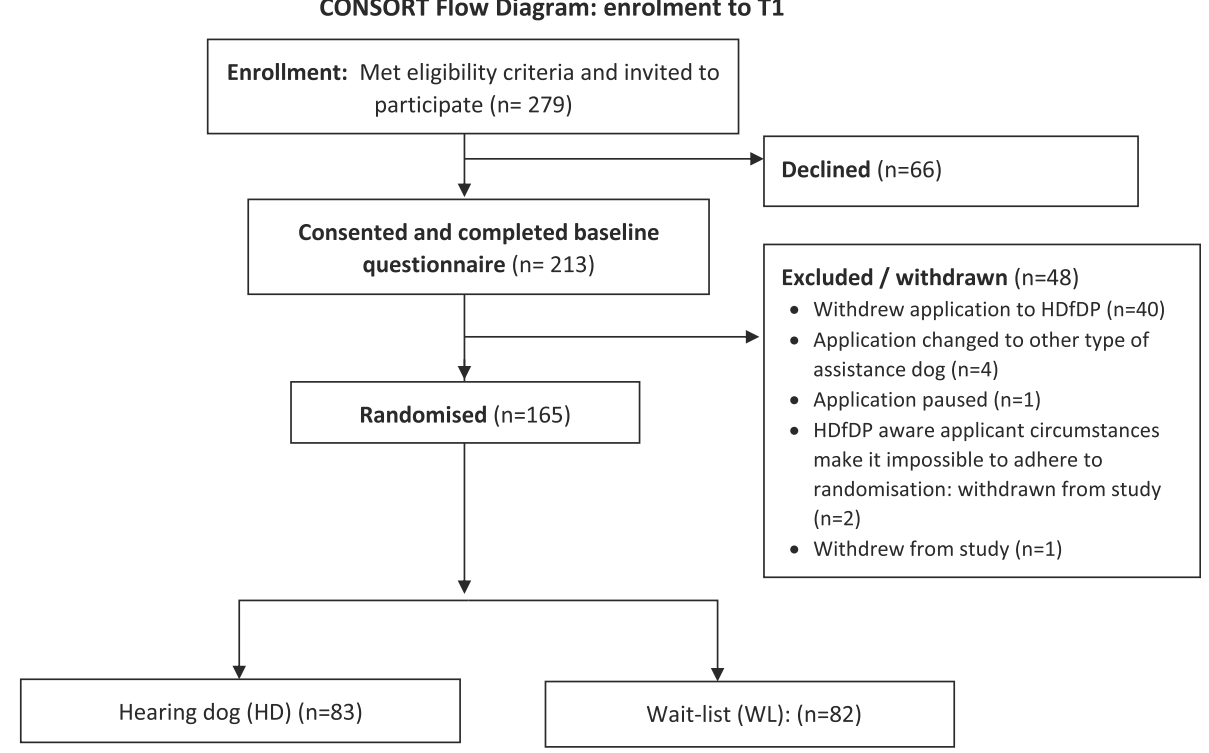

Fig. 1: CONSORT Flow Diagram: enrolment to T1 (primary endpoint) 


\section{Corrected Fig. 1}

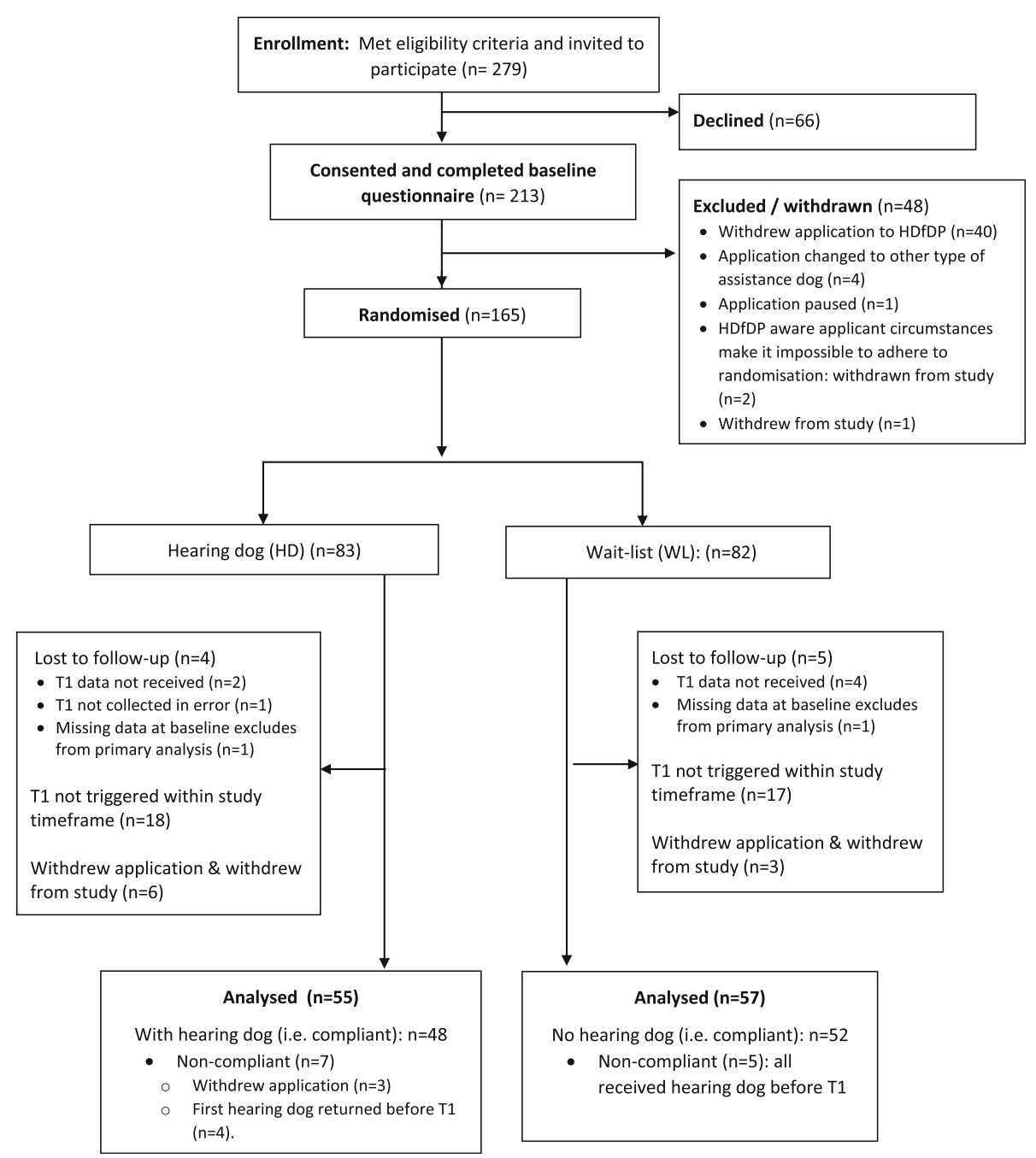

Fig. 1: CONSORT Flow Diagram: enrolment to T1 (primary endpoint)

2. The formatting of Table 4 in the pdf needed adjustments.

3. Background: the final sentence of fourth paragraph:

"However, this did not include study participants $(\mathrm{n}=3)$ with hearing dogs included in the effectiveness study [28]."

Should read:

"However, study participants $(\mathrm{n}=3)$ with hearing dogs were not included in the effectiveness study [28]."

The original article has been corrected.

\section{Author details}

${ }^{1}$ Social Policy Research Unit, Department of Social Policy and Social Work, Church Lane Building, York Science Park, University of York, York, Heslington YO10 5DF, UK. ${ }^{2}$ York Trials Unit, University of York, York YO10 5DD, UK. ${ }^{3}$ Centre for Health Economics, University of York, York YO10 5DD, UK.
Published online: 25 January 2022

\section{Reference}

1. Stuttard et al. (2021) Hearing dogs for people with severe and profound hearing loss: a wait-list design randomised controlled trial investigating their effectiveness and cost-effectiveness (2021) 22:700 DOl: https://doi. org/10.1186/s13063-021-05607-9 